\title{
VARIOUS FACTORS AFFECTING THE PELLET MORPHOLOGY, BROTH REOLOGY AND PECTINASE ENZYME PRODUCTION IN SUBMERGED FERMENTATION OF ASPERGILLUS SOJAE
}

\author{
ONCU S. ${ }^{(\text {a) }}$, UNLUTURK S. ${ }^{(a)}$, TARI C. ${ }^{(a)}$, GOGUS N. ${ }^{\text {(a) }}$ \\ (a) Izmir Institute of Technology, Gulbahce Koyu, Urla, 35430, Izmir, Turkey \\ email: selaleoncu@iyte.edu.tr, sevcanunluturk@iyte.edu.tr, \\ canantari@iyte.edu.tr,nihangogus@iyte.edu.tr
}

\begin{abstract}
Deep tank fermentations are widely used in the production of enzymes, antibiotics and organic acids, which have many applications in the food, medicine, pharmaceutical, chemical and textile industry (Mitard and Riba, 1987). The diverse range of commercially exploited fungal products, which have large contribution to the global economy is expanding enormously. However, their filamentous growth characteristic creates a number of process engineering problems attributed to the morphological change accounted during the fermentation process in large scales. This effects the maximum product and productivity of an enzyme. In this study, pectinase enyzme production was taken as a model for submerged fermentation. For this purpose, Aspergillus sojae strain which is not well known in the literature, was taken as a model organism and subjected to fermentation at $30^{\circ} \mathrm{C}$ for 96 hours to produce pectinase enzyme of commercial value. Composition of media, inoculation ratio and type, temperature and aeration rate was kept constant during fermentation. Experiments were conducted according to different dissolved oxygen concentrations, agitation speeds and $\mathrm{pH}$ in order to investigate the effects of these parameters on rheology, morphology and activity. As a result of these experiments, it was observed that small pellets gave higher activities under the conditions of low agitation speed, high dissolved oxygen concentrations and uncontrolled $\mathrm{pH}$.
\end{abstract}

Key words: Pellet morphology, broth rheology, pectinase enzyme, Aspergillus sojae

\section{INTRODUCTION}

The fungal culture exhibits two major morphologies observed as pellets which are spherical agglomerates of hyphaes or mycelia which is free mycelium dispersed throughout the culture medium. (Pedersen et al., 1993) These morphologies are very much determined by several environmental and genetic factors including type of organism, $\mathrm{pH}$ and composition of the 
media, inoculation ratio and type of the inoculum, agitation speed and aeration rate, feeding rate and genetic factors of the culture (Reichl et al., 1991; Pedersen et al., 1993; Li et al., 2000; Pazauki and Panda, 2000).

The metabolic performance of a microbial culture in the bioreactor depends strongly on complex interactions of the various operating conditions. For example, the agitation intensity, the microbial species being cultured, the nutrients type and supply determine the bulk rheology and cellular morphology. Rheology in turn affects supply of nutrients, specially oxygen, and the ease of mixing of the broth. Rheology-morphology relationships are particular relevant in fermentations involving filamentous fungi and bacteria. The specific growth morphology produced under given conditions depends on several factors including the fungal strain, the method of initiation of culture (e.g. spores, pellets, dispersed mycelium), the nature of the growth medium, and the hydrodynamic regime in the bioreactor (Metz and Kossen, 1977; Suijdam and Metz, 1981). Excessive hydrodynamic shear stresses are known to damage mycelial hyphae and pellets, but much lower shear stresses are sufficient to influence growth morphology.

In industrial applications pellet morphology is usually preferred in fermentations and in downstream processing due to the non viscous rheology of the broth (Atkingson and Daoud, 1976; Zhaou et al., 2000). In such fermentations, the mass transfer of oxygen and nutrients is considerably better and the subsequent separation of the pellets from the medium is simpler (Reichl et al., 1991). Since agitation and aeration is also much easier in such a system, the power input therefore the operating cost is lower.

However, in fermentations where the mycelia form is dominant and, the cell growth and productivity is higher, the broth is much more viscous, resulting in heterogeneous stagnant non - mixed zone formations, that are harder and more expensive to operate (Metz and Kossen, 1977). Hence, the morphology of the culture, which effects productivity and results into rheological changes of the broth, needs to be controlled. Therefore, the relationship between morphology and rheology and the factors influencing them have to be fully investigated.

The effects of aeration rate, agitation speed and dissolved oxygen concentration on pectinase production are important factors affecting successful progress of fermentation. Aeration could be beneficial to the growth and performance of microbial cells by improving the mass transfer characteristics with respect to substrate, product and oxygen (Martin and Bailey 1985; Olsvik and Kristiansen 1992; Rau et al. 1992; Cui et al. 1998; Sinha et al. 2001; Mantzouridou et al. 2002). Agitation is also an important parameter for adequate mixing, mass and heat transfer. Agitation creates shear forces, causing morphological changes, variation in their growth and product formation, and also damage to the cell structure (Taguchi et al. 1968; Martin and Bailey 1985; McNeil and Kristiansen 1987; Smith and Lilly 1990; Pfefferle et al. 2000; Mantzouridou et al. 2002; Park et al. 2002b).

Oxygen transfer limitations occur commonly in bioreactors, leading to decreased performance. Due to the poor solubility of oxygen in aqueous solutions, the dissolved oxygen (DO) supply in aerobic fermentations is usually viewed as a limiting step for product 
formation (Lai et al., 2002). When oxygen is limited, the metabolic rate of the microorganisms decreases significantly and the culture may respond adversely to the resulting stress (Lee, 1992).

The objective of this work is to examine the effect of dissolved oxygen, $\mathrm{pH}$ and agitation speed on the pellet morphology, broth rheology and pectinase production in submerged fermentation of Aspergillus sojae by keeping aeration rate, temperature, media composition, inoculation ratio and type constant.

\section{MATERIALS AND METHOD}

\section{Microorganism}

Aspergillus sojae ATCC 20235 was purchased from Procochem Inc., an international distributor of ATCC (American Type of Culture Collection) in Europe. The propagation of this culture was done on YME agar slant medium containing, malt extract at $10 \mathrm{~g} / \mathrm{l}$, yeast extract at $4 \mathrm{~g} / \mathrm{l}$, glucose at $4 \mathrm{~g} / 1$ and agar at $20 \mathrm{~g} / 1$ concentrations incubated at $30^{\circ} \mathrm{C}$ until well sporulated (1 week). Stock cultures of this strain were prepared with $20 \%$ glycerol water and stored at $-80^{\circ} \mathrm{C}$.

\section{Growth Medium}

For the seed medium, molasses media formulation (Glycerol (45 g/l), Pepton ( $18 \mathrm{~g} / \mathrm{l}$ ), Mollasses (45 g/l), $\mathrm{NaCl}(5 \mathrm{~g} / \mathrm{l}), \mathrm{FeSO}_{4} 7 \mathrm{H}_{2} \mathrm{O}(15 \mathrm{mg} / \mathrm{l}), \mathrm{KH}_{2} \mathrm{PO}_{4}(60 \mathrm{mg} / \mathrm{l}), \mathrm{MgSO}_{4}$ (50 $\mathrm{mg} / \mathrm{l}), \mathrm{CuSO}_{4} \cdot 5 \mathrm{H}_{2} \mathrm{O}(12 \mathrm{mg} / \mathrm{l}), \mathrm{MnSO}_{4} \cdot \mathrm{H}_{2} \mathrm{O}(15 \mathrm{mg} / \mathrm{l})$, Agar $\left.(20 \mathrm{~g} / \mathrm{l})\right)$ was used. Initially, the frozen stock cultures were inoculated on YME agar and incubated for one week at $30^{\circ} \mathrm{C}$ for activation. After this period a single isolate of the strain was inoculated on molasses slant and incubated for another week at the same temperature. Following the incubation period, $5 \mathrm{ml}$ of $0.01 \%(\mathrm{v} / \mathrm{v})$ tween 80 solution was added into the slant and harvested into empty sterile falcon tube and tested for sterility, viability and spore count. The spore counts were performed using Thoma bright line hemacytometer (Marienfield, Germany). The suspensions were stored at $4^{\circ} \mathrm{C}$ and used as inoculum for the fermentation process.

\section{Production Medium and Fermentation}

The fermentation was carried out in a $5 \mathrm{~L}$ bioreactor (New Brunswick BioFlo 3000, NJ, USA) with a working volume of $4 \mathrm{~L}$. The fermenter was equipped with two sets of a standard sixblade rushton impeller and four baffle plates. (The distance between two impellers is $108 \mathrm{~mm}$ and the distance to bottom impeller is $39 \mathrm{~mm}$ )

The fermentation media composition was prepared with corn steep liquor ( $5 \mathrm{~g} / \mathrm{l})$, peptone (5 $\mathrm{g} / \mathrm{l})$, maltrin $50(75 \mathrm{~g} / \mathrm{l})$, disodium phosphate $(3.2 \mathrm{~g} / \mathrm{l})$, monosodium phosphate $(3.3 \mathrm{~g} / \mathrm{l})$ and glucose $(0.75 \mathrm{~g} / 1)$ prepared in the amount of $4 \mathrm{~L}$. 
The inoculum amount into fermenter was $2 \times 10^{6}$ total spore. Depending on the spore count obtained from the spore suspension of the frozen culture, the inoculum was suspended with additional $10 \mathrm{ml}$ sterile water and transferred through sterile syringe into the fermenter.

The $\mathrm{pH}$ of the fermenter medium was maintained by using automatic control equipment, which added $6 \mathrm{~N} \mathrm{NaOH}$ of $10 \% \mathrm{H}_{2} \mathrm{SO}_{4}$ when $\mathrm{pH}$ deviated from the desired value.

When DO, rpm and $\mathrm{pH}$ were adjusted to desired values, the fermentation was started at $30^{\circ} \mathrm{C}$ by keeping aeration rate at $2.5 \mathrm{vvm}$. During this period, samples taken periodically were assayed for enzyme activity. Enzyme activity was determined on supernatant obtained after the centrifugation of the broth at $5000 \mathrm{rpm}$ for 15 minutes. At the end of the fermentation period (at 96 hours) fungal morphology and broth rheology were investigated.

\section{Enzyme Assay}

PG (polygalacturonase) activity was assayed according to the procedure given by Panda et al. (1999) by using $2.4 \mathrm{~g} / 1$ of polygalacturonic acid as substrate at $\mathrm{pH} 6.6$ and $26^{\circ} \mathrm{C}$. The amount of substrate and enzymes used were 0.4 and $0.086 \mathrm{ml}$ respectively. In this study, one unit of enzyme activity was defined as the amount of enzyme that catalyses the release of $1 \mu \mathrm{mol}$ of galacturonic acid per unit volume of culture filtrate per unit time at standard assay conditions. Galacturonic acid (Sigma, St. Louis, MO) was used as standard for calibration curve of PGase activity.

$$
\text { Activity }(\mathrm{U} / \mathrm{ml})=(\mathrm{mg} \text { of galacturonic acid /212.12) } \times(1 / 20) \times(1 / 0.086)
$$

\section{Rheological and Morphological Measurements}

Rheological properties of fermentation broth were determined by using concentric cylinder viscometer (Brookfield DV II + Pro, Brookfield Engineering Lab. Inc., MA, USA) equipped with a cylindrical spindle (cylinder diameter $18.84 \mathrm{~mm}$, length $115 \mathrm{~mm}$, beaker diameter $86.30 \mathrm{~mm}$ and $600 \mathrm{ml}$ of sample volume). The cylindrical spindle geometry was used for the samples taken at the end of the fermentation period (at $96 \mathrm{~h}$ ). On the other hand, small sample and UL adapter attachments are used for the samples taken periodically during fermentation period. But in these samples the size of pellets was generally of the same order of magnitude as the annulus of the UL and small sample adapter. In order to overcome this measurement problem, the measured viscosity of fermentation broth was assumed to be a suspension and corrected by using a mathematical model developed by Metzner (1985).

The model for estimating viscosity of dilute suspensions was based on volume fraction of the suspended solids (pellet) $(\phi)$ and the relative viscosity of the suspension, given in Equation 2 
and 3, where $\eta$ was the viscosity of the suspension and $\eta_{s}$ was the viscosity of the continuous phase (Metzner, 1985):

$$
\begin{gathered}
\eta_{r}=\frac{\eta}{\eta_{s}} \\
\eta_{r}=\left[1-\left(\frac{\phi}{A}\right)\right]^{-2}
\end{gathered}
$$

In equation 3, A was in the range of 0.44 and 0.68 for the crystal and spherical shape particles. For this purpose, the volume and mass of the each sample containing spherical pellets was initially measured and the bulk density of the suspension (fermentation broth) was calculated. Then the sample was filtered and mass and volume measurements were repeated for the filtrate (clear broth). Volume fractions $(\phi)(\mathrm{v} / \mathrm{v})$ were calculated from these measurements. After, the viscosity of the clear broth, $\eta_{s}$, was measured by using viscometer and suspension viscosity $\eta$ was calculated from equation 3 .

Pellet morphology (pellet number and size) was characterized by using image analysis (Cox and Thomas, 1992). Pellet particles were analyzed for determination of the number of pellet per given volume and pellet size by fixing the samples with a fixative $(13 \mathrm{ml}$ of $40 \%$ formaldehyde, $5 \mathrm{ml}$ glacial acetic acid, $200 \mathrm{ml}$ of 50\% ethanol) (Park et al., 2002).

The image was captured with a eurocam (Euromax, Holland) mounted on a phase contrast microscope (Novex, Holland). Image analysis was performed with the software package Image - Pro Plus 4.5.1. (Media Cybernetics Inc., Silver Spring, MD, USA). The size of the pellet was quantified using the diameter corresponding to a circular area equivalent to the pellet projected area (Lopez et al., 2005).

\section{RESULTS AND DISCUSSION}

In this study, the effects of $\mathrm{pH}$, dissolved oxygen concentration (DO) and agitation speed on broth rheology, pellet morphology and activity were investigated. At all experiments, media composition, temperature, inoculation ratio and type, aeration rate and starting parameters were kept the same.

\section{The effect of $\mathrm{pH}$}

In order to investigate the effect of $\mathrm{pH}$, two experiments were conducted. In the first experiment $\mathrm{pH}$ was kept at 6 and in the second one $\mathrm{pH}$ was not controlled. In both experiments DO was kept at 50\%, through cascading the agitation speed between 200 and $500 \mathrm{rpm}$. In the first experiment, it was not possible to measure the viscosity of the broth by using spindle geometry so that rheological measurement was conducted with UL adapter, filtrate and suspension viscosity values were calculated according to Metzner model (Eqn. 3) and comparison was made for two experiments. 
Table 1. The effect of $\mathrm{pH}$ on rheology, morphology and enzyme activity

\begin{tabular}{|l|l|l|}
\hline & Un controlled $\mathrm{pH}$ & $\mathrm{pH}=6.0$ \\
\hline $\begin{array}{l}\text { Viscosity (cP) (at 73.38 1/s) } \\
\text { Fuspension }\end{array}$ & 3.20 & 4.20 \\
\hline Pellet volume fraction & 1.04 & 1.79 \\
\hline Pellet number/1 g media & 9.26 & 0.20 \\
\hline $\begin{array}{l}\text { Enzyme Activity }(\mathrm{U}) \\
\text { at } 50 \text { h }\end{array}$ & 7.34 & 74 \\
at 96 h & 4.64 & 3.97 \\
\hline Pellet morphology & $\begin{array}{l}\text { Small pellets with dense } \\
\text { core with a fluffy region } \\
\text { surrounding the core }\end{array}$ & $\begin{array}{l}\text { Small and compact smooth } \\
\text { very dense pellets }\end{array}$ \\
\hline Average pellet size $(\mathrm{mm})$ & $1.69 \pm 0.48$ & $1.95 \pm 0.46$ \\
\hline $\begin{array}{l}\text { Biomass dry wieght }(\mathrm{g} / \mathrm{L}) \text { at } \\
\text { 96 h }\end{array}$ & 8.75 & 11.62 \\
\hline
\end{tabular}

It was observed that the suspension viscosity was higher when $\mathrm{pH}$ was set to 6 (Table 1). Although pellet volume fraction and number of pellet formation was not high, the filtrate viscosity was found to be slightly higher in the medium where $\mathrm{pH}$ was kept at 6.0, which imposed an effect on the suspension viscosity calculations. This could be attributed to the production and secretion of some metabolites into the medium by this micro-organism. This might have had also an influence on the enzyme activity. The enzyme was deactivated at the end of the fermentation period when $\mathrm{pH}$ was kept at 6 . On the other hand, the activity was found to be higher for the uncontrolled $\mathrm{pH}$ medium and the maximum activity was reached at 45 hour in both fermentations. When $\mathrm{pH}$ gets lower (acidic medium) nutrients are better and can be easily used by microorganisms and bigger pellets are formed. For this reason enzyme activity is higher when $\mathrm{pH}$ is lower. Additionally, $\mathrm{pH}$ did not significantly affect the average pellet size, pellet number and pellet size distribution (data not given) but created a higher impact on the morphology (pellets with a hairy region surrounding a dense core or compact, smooth and very dense pellets) (Fig 1). In the fermentation run where $\mathrm{pH}$ was not controlled, at the end of $96 . \mathrm{h}, \mathrm{pH}$ of the medium decreased to 4.0

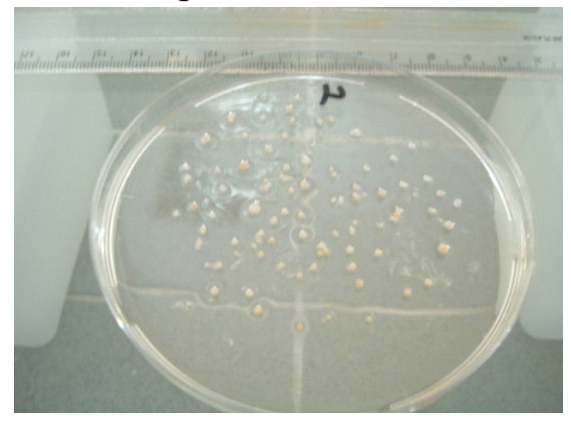

a) $\mathrm{pH}$ uncontrolled

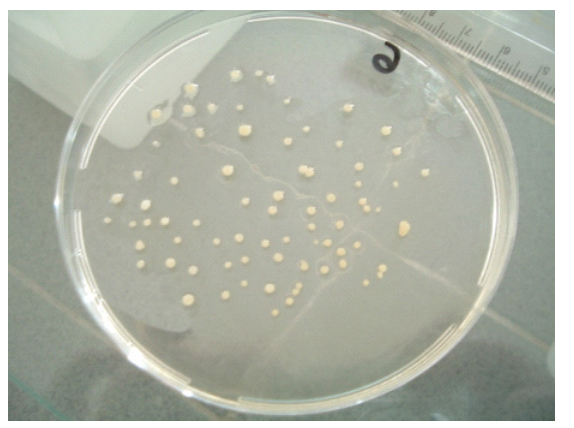

b) $\mathrm{pH}=6$

Figure 1. Pellet morphologies when a) $\mathrm{pH}$ was uncontrolled and b) $\mathrm{pH}$ was at 6 in $1 \mathrm{~g}$ of broth 


\section{The Effect of Dissolved Oxygen (DO) Concentration}

In order to study the effect of dissolved oxygen concentration (at $30 \%$ and $50 \%$ ) same experimental conditions as described in materials and methods were applied, with only the difference where $\mathrm{pH}$ of the medium was adjusted initialy to $\mathrm{pH} 6$ and afterwards not controlled..), Agitation speed was cascaded between 200-500 rpm in order to keep the dissolved oxygen concentration at 30 and $50 \%$. The results are given in figure 2, 3 and 4 .

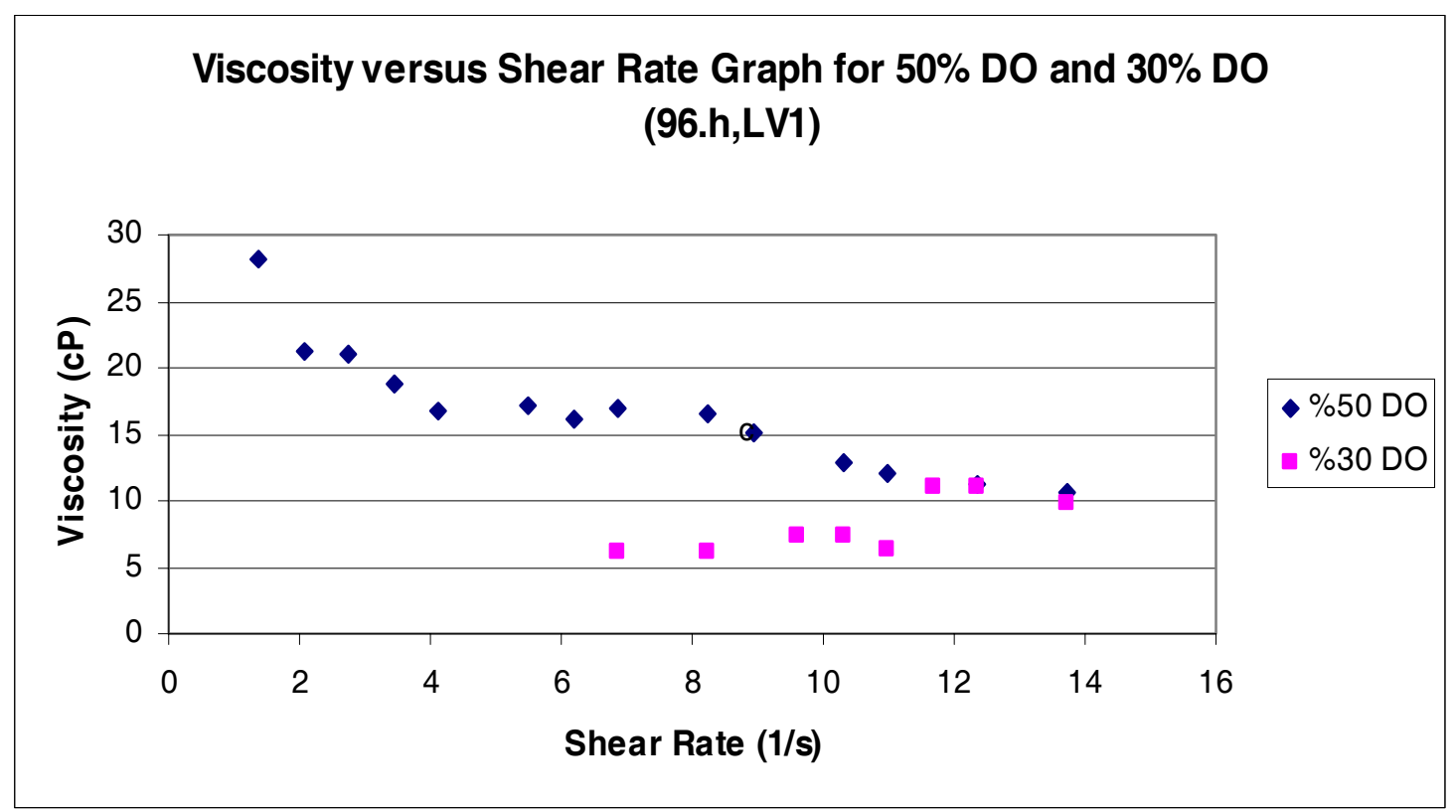

Figure 2. The effect of DO on rheology (viscosity as a function of shear rate)

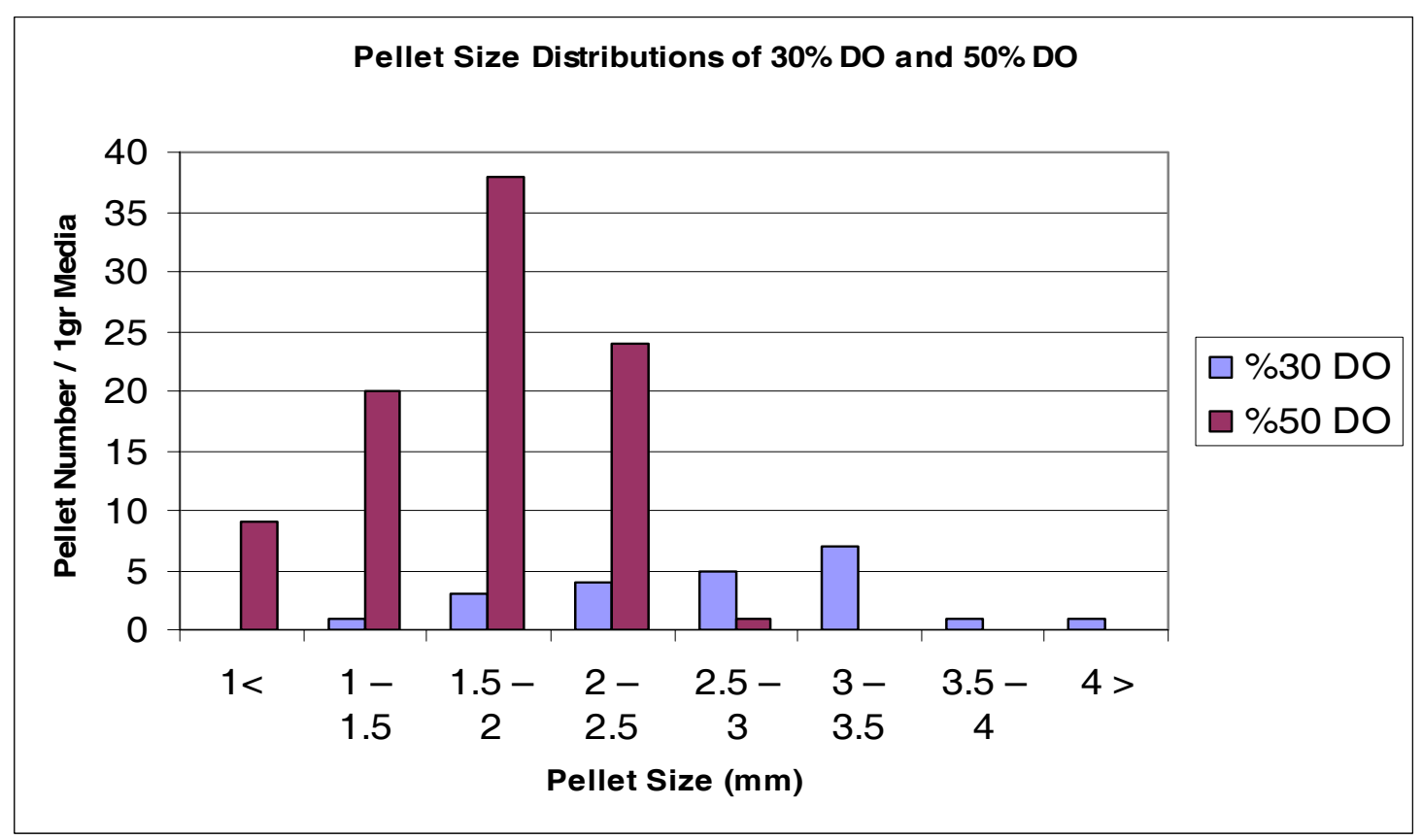

Figure 3. The effect of DO on pellet size distribution 
Non-Newtonian behavior was observed for both DO concentrations. While medium at $30 \%$ DO was exhibiting non-Newtonian and dilatant behavior, 50\% DO medium was showing non-Newtonian and pseudoplastic behavior (Fig.2). Flow behavior index (n) and consistency index (K, Pa.s) values for 30\% DO medium and 50\% DO medium were found to be 1.88 and 0.0039 Pa.s, 0.63 and 0.12 Pa.s, respectively. Dilatancy (i.e. $\mathrm{n}>1$ ) might be due to adhesion of hairy and large pellets to form big clumps exhibiting high resistance to increased shear rates or sedimentation of heavy particles during viscosity measurements (Fig.4). The average pellet size for $30 \%$ DO and $50 \%$ DO medium was found to be $2.8 \pm 0.87 \mathrm{~mm}$ and $1.69 \pm 0.48 \mathrm{~mm}$, respectively. Higher DO concentration resulted in small pellet formation with a high pellet number (Fig. 3). The maximum activities were $7.34 \mathrm{U}$ and $6.26 \mathrm{U}$ for $50 \% \mathrm{DO}$ medium and $30 \%$ DO medium, respectively. In summary, large pellet formation, lower viscosity and enzyme activity were observed in $30 \%$ DO concentration medium. On the other hand, high DO concentration medium (50\%) assisted to form small pellets of high in numbers which resulted in higher enzyme activity.

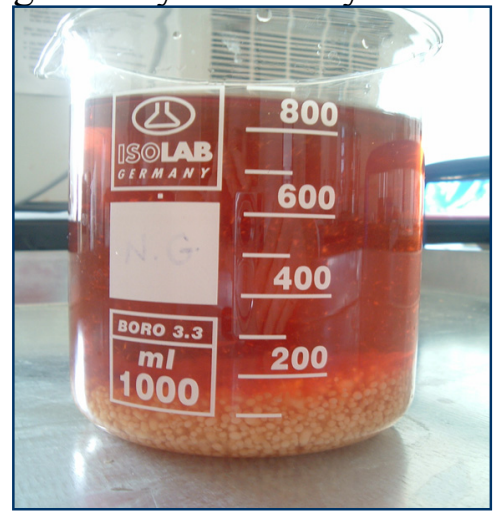

a) $30 \% \mathrm{DO}$

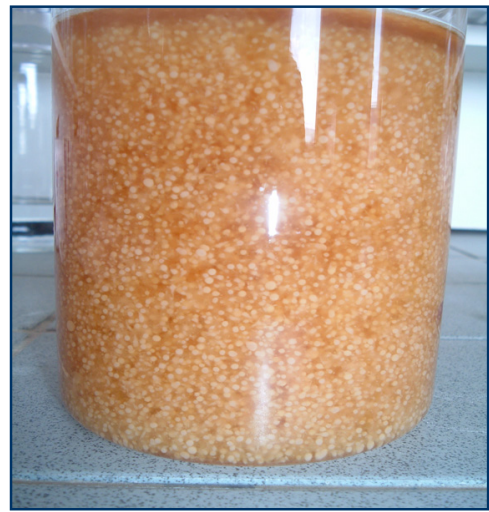

b) $50 \% \mathrm{DO}$

Figure 4. Pellet morphologies of a) $30 \% \mathrm{DO}$ and b) $50 \% \mathrm{DO}$ in $600 \mathrm{ml}$ beaker

\section{The Effect of Agitation Speed}

In order to investigate the effect of agitation speed on the enzyme activity, pellet morphology and rheology, fermentations were carried out at $350 \mathrm{rpm}$ and at $200 \mathrm{rpm}$ agitation speeds. All the other fermentation conditions were kept the same (inoculation rate- $2 \times 10^{6}$ total spore, $50 \%$ $\mathrm{DO}$, uncontrolled $\mathrm{pH}$, aeration rate- $2.5 \mathrm{vvm}$ ).

Table 2. The effect of agitation on morphology and enzyme activity

\begin{tabular}{|l|l|l|}
\hline Agitation speed & $200 \mathrm{rpm}$ & $300 \mathrm{rpm}$ \\
\hline Pellet number/1 g media & 122 & 13 \\
\hline $\begin{array}{l}\text { Maximum enzyme activity } \\
(\mathrm{U})\end{array}$ & 6.73 & 4.39 \\
\hline Pellet morphology & Small pellets & Large and loose pellets \\
\hline Average pellet size $(\mathrm{mm})$ & $0.70 \pm 0.34$ & $1.70 \pm 0.90$ \\
\hline $\begin{array}{l}\text { Biomass dry weight }(\mathrm{g} / \mathrm{L}) \text { at } \\
96 \mathrm{~h}\end{array}$ & 8.2 & 6.75 \\
\hline
\end{tabular}




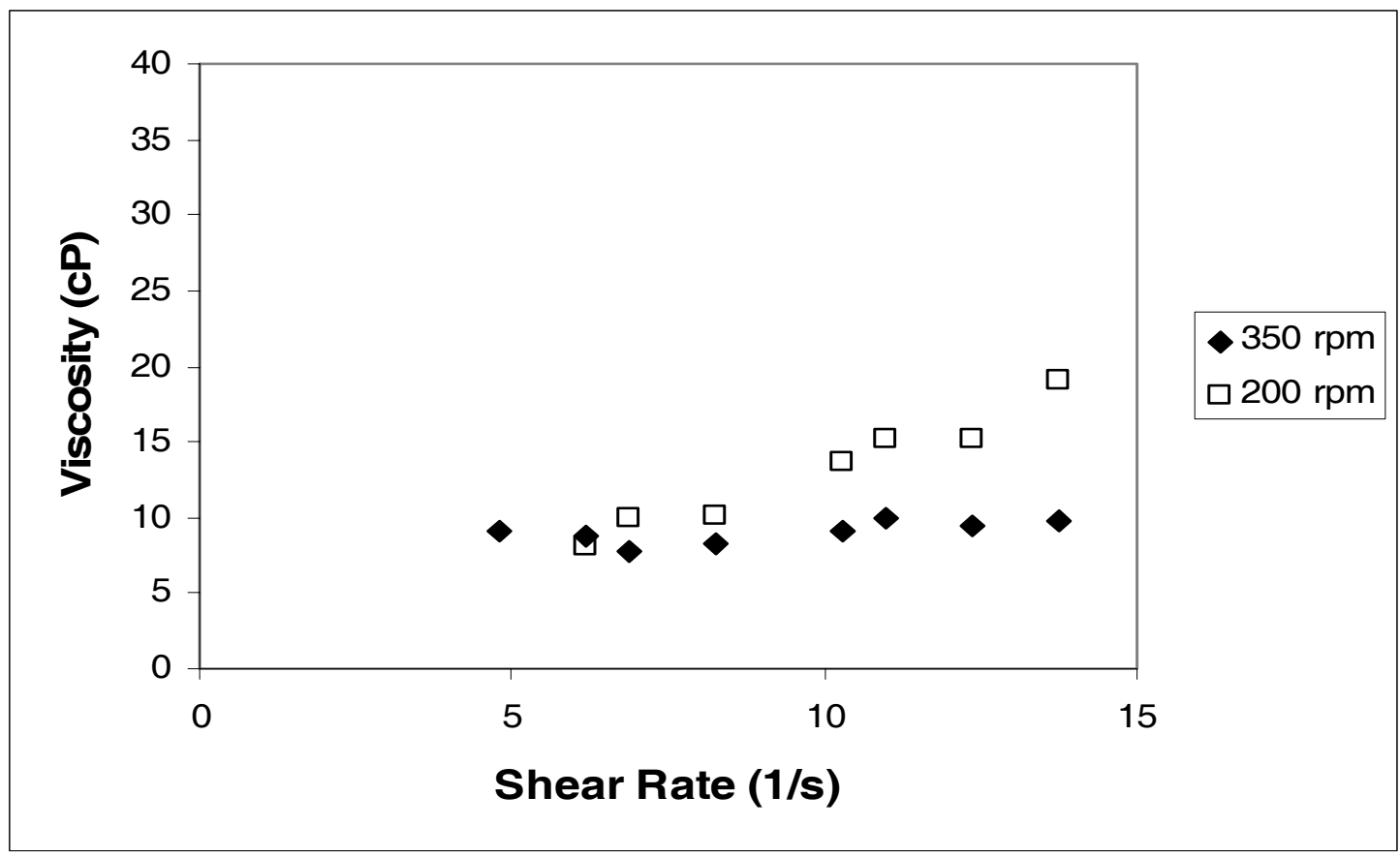

Figure 5. The effect of agitation speed on broth rheology

Non-Newtonian and dilatant behavior ( $\mathrm{n}=1.98$ and $\mathrm{K}=0.0054$ Pa.s) (Fig.5) and, small pellet formation was observed at $200 \mathrm{rpm}$ (Table 2).Additionally, pellet number per $1 \mathrm{~g}$ media was found to be very high at $200 \mathrm{rpm}$. Small pellets had a tendency to stick together to form a flock massiveness when the shear rate was increased. This caused a big resistance to flow and resulted in dilatant behavior with increased shear rates. On the other hand, Newtonian type of behavior was detected at $350 \mathrm{rpm}$. A mixture of loose, large and dense pellets and free filaments were observed in this medium. In many reports, it is claimed that high agitation rate creates higher shear forces and reduces agglomeration of hyphal elements and reducing both pellet diameter and the concentration of pellets (Papagianni, 2004). Although the number of pellets in the culture agitated at $350 \mathrm{rpm}$ was low as indicated in these reports, A. sojae formed loose and large pellets quite the opposite of literature data. In addition, the biomass dry weight of the culture having loose and large pellets was in the same order of magnitude with the culture having small pellets. This may be explained by increased oxygen transfer rate due to high agitation in Newtonian medium which promoted the growth of pellets. Moreover, maximum enzyme activity was found to be $6.73 \mathrm{U}$ and $4.39 \mathrm{U}$ at $200 \mathrm{rpm}$ and 350 rpm, respectively. Consequently, the cultures of small pellets yielded higher levels of enzyme activity than did the cultures composed mainly of free filaments and loose pellets.

\section{CONCLUSION}

It was found that pellet morphology, broth rheology and pectinase enzyme production from Aspergillus sojae depended on the $\mathrm{pH}$, dissolved oxygen concentration and agitation speed. When small dense pellets were formed, the pectinase production was the highest.

This work is a preliminary study to understand and obtain more information about the fermentation conditions of this strain used the first time for pectinase production in a 
submerged fermentation. The optimization conditions and oxygen transfer phenomena need to be examined in more detailed in future studies.

\section{REFERENCES}

Atkingson B. and Daoud L.S., 1976, Microbial flogs and flocculation in fermentation process engineering, Adv. Biochem. Eng., 4: 41-124.

Cox P.W. and Thomas C.R., 1992, Classification and measurement of fungal pellets by automated image analysis, Biotechnol. Bioeng., 39: 945-952.

Cui, Y.Q., van der Lans, R.G.J.M. and Luyben, K.Ch.A.M., 1998, Effects of dissolved oxygen tension and mechanical forces on fungal morphology in submerged fermentation, Biotechnology and Bioengineering, 57: 745-790.

Lee JM., 1992, Biochemical engineering, Englewood Cliffs, NJ: Prentice- Hall. p 240.

Li Z.J., Shukla V., Fordyce A.P., Pedersen A.G., Wenger K.S. and Marten M.R., 2000, Fungal morphology and fragmentation behaviour in a fed-batch Aspergillus oryzae fermentation at the production scale, Biotechnol. Bioeng., 70: 300-312.

Lopez J.L.C., Perez J.A.S., Sevilla J.M.F., Porcel E.M.J. and Chisti Y. Y., 2005, Pellet morphology, culture rheology and lovastation production in cultures of Aspergillus terreus, J. Biotechnol., 116: 61-77.

Mantzouridou, F., Roukas, T. and Kotzekidou, P., 2002, Effect of the aeration rate and agitation speed on b-carotene production and morphology of Blakeslea trispora in a stirred tank reactor: mathematical modelling, Biochemical Engineering Journal, 10: $123-135$.

Martin, A.M. and Bailey V.I., 1985, Growth of Agaricus campestris NRRL 2334 in the form of pellets, Applied and Environmental Microbiology, 49: 1502-1506.

McNeil, B. and Kristiansen, B., 1987, Influence of impeller speed upon the pullulan fermentation, Biotechnology Letters, 9: 101-104.

Metz, B., Kossen, N.W.F., 1977, The growth of molds in the form of pellets - a literature review, Biotechnol. Bioeng. 19: 781-799.

Metzner A.B., 1985, Rheology of suspensions in polymeric liquid, Society Rheology, 29(6): 739-775.

Mitard A. and Riba J.P., 1987, Morphology and growth of Aspergillus niger ATCC 26036 cultivated at several shear rates, Biotechnol. Bioeng., 32: 835-840. 
Olsvik, E.S. and Kristiansen, B., 1992, Influence of oxygen tension, biomass concentration, and specific growth rate on the Rheological properties of a filamentous fermentation broth, Biotechnology and Bioengineering 40: 1293-1299.

Panda T., Naidu G.S.N. and Sinha J., 1999, Multiresponse analysis of microbiological parameters affecting the production of pectolytic enzymes by Aspergillus niger: a statistical view, Process Biochem., 35: 187-195.

Papagianni M., 2004, Fungal morphology and metabolite production in submerged mycelial processes. Biotechnology Advances, 22: 189-259

Park J.P., Kim Y.M., Kim S.W., Hwang H.J., Cho Y.J., Lee Y.S., Song C.H. and Yun J.W., 2002, Effect of aeration rate on the mycelial morphology and exo-biopolymer production in Cordyceps militaris, Process Biochem., 37: 1257-1262.

Park, J.P., Kim, Y.M., Kim, S.W., Hwang, H.J., Cho, Y.J., Lee, Y.S., Song, C.H. and Yun, J.W., 2002b, Effect of agitation intensity on the exo-biopolymer production and mycelial morphology in Cordyceps militaris, Letters in Applied Microbiology, 34: 433438.

Pazauki M. and Panda T., 2000, Understanding the morphology of fungi, Bioprocess Eng., 22: 127-143.

Pedersen, A.G.; Bundgaard-Nielsen, M.; Nielsen, J.; Villadsen, J. and Hassager, O., 1993, Rheological Characterization of Media Containing Penicillium chrysogenum, Biotechnology and Bioengineering, 41, 162

Pfefferle, C., Theobald, U., Gurtler, H. and Fiedler, H.-P., 2000, Improved secondary metabolite production in the genus Streptosporangium by optimization of the fermentation conditions, Journal of Biotechnology, 80: 135-142.

Rau, U., Gura, E., Olszewski, E. and Wagner, F., 1992, Enhanced glucan formation of filamentous fungi by effective mixing, oxygen limitation and fed-batch processing, Journal of Industrial Microbiology, 9: 19-26.

Reichl U., King R. and Gilles E.D., 1991, Characterization of pellet morphology during submerged growth of Streptomyces tendae by image analysis, Biotechnol. Bioeng., 39: $164-170$.

Sinha, J., Bae, J.T., Park, J.P., Kim, K.H., Song, C.H. and Yun, J.W., 2001, Changes in morphology of Paecilomyces japonica and their effect on broth rheology during production of exo-biopolymers, Applied Microbiology and Biotechnology, 56: 88-92.

Smith, J.J. and Lilly, M.D., 1990, The effect of agitation on the morphology and penicillium production of Penicillium chrysogenum, Biotechnology and Bioengineering, 35: 10111023. 
Suijdam, J.C., Metz, B., 1981, Influence of engineering variables upon the morphology of filamentous molds, Biotechnol. Bioeng. 23: 111-148.

Taguchi, H., Yoshida, T., Tomita, Y. and Teramoto, S., 1968, The effects of agitation on disruption of the mycelial pellets in stirred fermentors, Journal of Fermentation Technology, 46: 814-822.

Zhaou Y., Du J. and Tsao G.T., 2000, Mycelial pellet formation by Rhizopus oryzae ATCC 20344, Appl. Biochem. Biotechnol., 84-86: 779-789. 